\title{
Pengelolaan dan Pengembangan Aset Masjid Sebagai Upaya Peningkatan Layanan Ibadah
}

\section{Management and Development of Masjid Assets as Efforts for Improving Worship Services}

\author{
${ }^{1 *}$ Noni Setyorini, ${ }^{2}$ Qristin Violinda \\ ${ }^{1,2)}$ Program Studi Manajemen, Fakultas Ekonomi dan Bisnis \\ Universitas PGRI Semarang \\ Jl Sidodadi Timur No.24 Semarang \\ *email: nonisetyorini@gmail.com
}

DOI:

10.30595/jppm.v5i1.6343

Histori Artikel:

Diajukan:

07/01/2020

Diterima:

$21 / 05 / 2021$

Diterbitkan:

08/07/2021

\section{ABSTRAK}

Strategi pengelolaan masjid adalah suatu usaha optimalisasi peran dan fungsi masjid agar kehadirannya dapat bermanfaat bagi jamaah dan masyarakat. Upaya-upaya tersebut tentu saja harus dilakukan secara berkelanjutan dengan mempertimbangnkan aspek etika dan nilai-nilai syariah yang bersifat ritual. Strategi pengelolaan masjid yang baik adalah berbasis jamaah karena akan berdampak pada peningkatan pelayanan masjid terhadap jamaahnya dan jamaah masjid akan tertarik untuk berpartisipasi bersama-sama pengelola dalam memakmurkan masjid. Apabila pengelolaan masjid masih bersifat tradisional, maka masjid tidak akan terberdayakan dan hanya menjadi tempat ritual ibadah. Oleh karena itu, pengabdian ini bermaksud memberikan edukasi kepada para remaja masjid agar secara kreatif dan profesional melakukan pengelolaan masjid. Metode pengabdian yang dilakukan adalah dengan melakukan pembinaan terkait aspek keuangan, SDM, dan asset masjid. Diharapkan, pengeloaan dan manajemen ini dapat dipraktekkan dengan baik, mudah, dan profesional, sehingga masjid membawa keberkahan bagi sekitar.

Kata kunci: Manajemen; Aset; Pengelolaan; Masjid

\begin{abstract}
The mosque management strategy is an effort to optimize the role and function of the mosque so that its presence can benefit the congregation and the community. Of course, these efforts must be carried out in a sustainable manner by considering the ethical aspects and ritualistic values of sharia. A good mosque management strategy is congregational-based because it will have an impact on improving mosque services to the congregation and the congregation will be interested in participating together with the manager in prospering the mosque. However, if the mosque management is still traditional in nature, the mosque will not be empowered and will only become a place of ritual worship. Therefore, this service aims to provide education to mosque youths so that they can creatively and professionally manage the mosque. The service method used is to provide guidance related to financial aspects, human resources, and mosque assets. The hope of the management and management servants can be practiced properly, easily and professionally, so that the mosque brings blessings to those around.
\end{abstract}

Keywords: Management; Asset; Supervision; Mosque 


\section{PENDAHULUAN}

Masjid merupakan tempat orang berkumpul dan melakukan shalat secara berjamaah dengan tujuan sebenarnya adalah meningkatkan solidaritas dan silaturahmi diantara kaum muslim (Dalmeri, 2014). Secara teoritis-konseptual, masjid adalah kebudayaan Islam. Dari tempat inilah syiar Islam yang meliputi aspek duniawi dan ukhrawi, materialspritual dimulai. Masjid menempati posisi sangat istimewa dalam doktrin dan kultur Islam, sebab masjid menjadi pilar spiritual yang menyangga kehidupan duniawi umat (Fahmi \& Qulub, 2017). Masjid memiliki peranan strategis untuk kemajuan peradaban umat muslim, sejarah telah membuktikan multi fungsi peranan masjid tersebut (Sofwan, 2013).

Strategi pengelolaan masjid adalah suatu usaha optimalisasi peran dan fungsi masjid agar kehadirannya dapat dirasakan manfaatnya bagi jamaah pada khususnya dan masyarakat sekitar pada umumnya (Sofwan, 2013). Upaya-upaya tersebut tentu saja harus dilakukan secara kontinyu dengan mempertimbangnkan aspek etika dan nilainilai syariah yang bersifat ritual. Strategi pengelolaan masjid yang baik adalah berbasis jamaah, karena akan berdampak pada peningkatan pelayanan masjid terhadap jamaahnya dan sudah barang tentu jamaah masjid akan tertarik untuk berpartisipasi bersama-sama pengelola dalam memakmurkan masjid (Ikhwan, 2013). Sebaliknya, apabila pengelolaan masjid masih bersifat tradisional maka masjid akan sulit untuk dapat memberdayakan jamaahnya.

Fungsi masjid harus diberdayakan secara profesional baik dari aspek pembinaan keagamaan dan sosial maupun dari segi fisik seperti pemanfaatan ruang-ruang masjid (Alwi, 2015). Tempat dan lahan yang ada di lingkungan masjid digunakan untuk hal-hal yang dapat memberikan manfaat bagi kemakmuran masjid maupun untuk kepentingan jamaah masjid dan masyarakat sekitar (Abshari, 2016). Namun sayangnya, saat ini pengelolaan masjid dilakukan (asalasalan) atau (asal jalan) dan sekedar melaksanakan administrasi masjid secara konvensional. Padahal akan lebih baik jika dilakukan dengan menggunakan manajemen modern.

Masjid dapat menjadi sentral kekuatan masyarakat. Di masa lalu, pada masa Nabi, masjid dapat diperankan secara maksimal sebagai sentral masyarakat Islam untuk berbagai kegiatan (Auliyah, 2014). Pada saat sekarang, masjid memiliki fungsi sebagai tempat ibadah/pembinaan iman/taqwa, sosial kemasyarakatan, peningkatan pendidikan dan pembinaan Sumber Daya Manusia (SDM) serta pengembangan ekonomi. Umumnya dari empat fungsi ini hanya yang pertama saja yang terlaksana, sementara fungsi lainnya belum optimal (Sofwan, 2013).

Upaya untuk mengoptimalkan fungsi tersebut perlu dilakukan identitifikasi untuk meningkatkan kapasistas masjid dan pengurusnya untuk mampu menjalankan fungsinya (Ridwanullah \& Herdiana, 2018). Potensi pemberdayaan ekonomi masyarakat berbasis masjid sangat diperlukan sebagai motor penggerak, kondisi ini didasari dari fungsi masjid bukan saja sebagai tempat ibadah tetapi juga dapat menjalankan fungsi sosial ekonomi, maka sudah barang tentu masjid yang memiliki ekonomi potensial dapat digerakkan menjadi ekonomi produktif dalam rangka pengentasan kemiskinan sehingga kualitas hidup masyarakat menjadi lebih baik (Jannah, 2016).

Mitra kegiatan pengabdian ini yaitu Remaja Masjid Al-Ikhlas Jl. Slamet Riyadi, Gayamsari, Kota Semarang, Jawa Tengah 50248. Berdasarkan hasil survey dan wawancara diperoleh beberapa permasalahan, yang dapat dilihat pada Tabel 1. Dalam menentukan permasalahan, tim pengabdian telah melakukan koordinasi dengan mitra untuk mengetahui masalah dan potensi yang dimiliki sehingga mampu digunakan sebagai solusi dalam rangka ikut memecahkan permasalahan lingkungan di masyarakat. 
Noni Setyorini, Qristin Violinda

Pengelolaan dan Pengembangan Aset Masjid Sebagai Upaya Peningkatan Layanan Ibadah

Tabel 1. Permasalahan Mitra Kelompok

\begin{tabular}{lll}
\hline No & \multicolumn{2}{l}{ PERMASALAHAN MITRA } \\
\hline 1 & Manajemen & Struktur belum \\
& organisasi & optimal \\
2 & Pengelolaan Asset & Kurang optimal \\
3 & Jaringan social & Belum ada \\
\hline
\end{tabular}

\section{METODE}

Metode pendekatan yang digunakan adalah pemberdayaan dengan menggunakan beberapa tahapan/ langkah. Tahapan kegiatan pengabdian adalah sebagai berikut:

\section{A. Tahap Persiapan}

Program ini dilaksanakan untuk meningkatkan pengetahuan masyarakat setempat tentang pengelolaan aset masjid terhadap lingkungan sekitar. Oleh karena itu diperlukan pemberdayaan masyarakat setempat untuk berpartisipasi aktif dalam program ini.

1. Tim Pengabdian UPGRIS telah Melakukan Kerjasama dengan Pengelola dan Remaja Masjid Al-Ikhlas Gayamsari.

Tahap awal yang dilakukan adalah melakukan kerjasama dengan masyarakat setempat, dalam hal ini adalah ketua Yayasan Masjid Al-Ikhlas Gayamsari. Dalam diskusi tersebut, telah disampaikan maksud dan tujuan dari program serta meminta izin merealisasikan program ini di kawasan tersebut. Selain itu, dalam diskusi dijelaskan teknis kegiatan yang akan dilakukan yaitu berupa sosialisasi langsung ke masyarakat mengenai pengelolaan asset masjid secara professional.

2. Persiapan Alat dan Bahan yang Akan Digunakan

Tahap selanjutnya yang dilakukan adalah menyiapkan alat dan bahan yang akan digunakan.

\section{B. Tahap Pelaksanaan}

Dalam proses pelaksanaan, narasumber, tim pengabdian, dan pengelola masjid berkumpul bersama untuk melaksanakan program yang terbagi menjadi dua tahap, yaitu:
1. Sosialisasi dan penjelasan tentang manajemen aset, serta dampak terhadap pengelolaan aset.

2. Pelatihan pengelolaan aset agar meningkatkan layanan ibadah.

\section{Tahap Akhir}

Tahap ini merupakan proses follow up dan controlling untuk menindaklanjuti terkait dengan pengelolaan aset masjid yang sudah dilakukan. Disamping itu, pada tahap ini, dijelaskan pula keuntungan jika menerapkan manajemen secara profesional. Masyarakat diharapakan dapat memahami dan mempraktekkan cara mengelola asset secara profesional dan kontinue.

\section{HASIL DAN PEMBAHASAN}

Masjid Al Ikhlas Gayamsari terletak di Jl Slamet Riyadi No.18 Gayamsari, Semarang. Masjid berdiri sejak tahun 1986 di atas tanah wakaf seluas $1.044 \mathrm{~m}^{2}$ dengan bangunan seluas $800 \mathrm{~m}^{2}$. Masjid Al Ikhlas memiliki jamaah yang sangat banyak sekitar 200 jamaah. Fasilitas yang dimiliki masjid juga sangat banyak, masjid memiliki gedung untuk TK, TPQ, perpustakaan, museum kecil dan ruang pertemuan.

Banyaknya aset yang dimiliki oleh masjid membutuhkan program dan manajemen yang baik agar pengelolaan masjid dapat berjalan dengan baik. Berdasarkan hal tersebut maka pengabdian yang dilaksanakan oleh Tim Pengabdian UPGRIS telah menjalankan 3 program. Proses pelatihan dibagi menjadi 3 sesi dan dipaparkan oleh dosen dengan spesialisasi masing-masing. Pelatihan dihadiri oleh pengurus masjid yaitu remaja masjid dan pengurus yayasan Masjid Al Ikhlas Gayamsari.

Pada sesi pertama, remaja masjid diajarkan proses pengelolaan harta benda masjid yang dilaksanakan dengan menjelaskan proses pengelolaan harta benda yang dimiliki oleh masjid. Harta benda masjid yang dimiliki sangat banyak misalnya mic, sound, LCD, TV, dan lemari. Pada saat penjelasan tentang pengelolaan tersebut, pelatih mengajarkan proses manajemen penjadwalan untuk kebersihan, dan pencatatan banda (harta) yang dimiliki oleh masjid. Hal tersebut 
dimaksudkan agar harta benda yang dimiliki masjid dapat dievaluasi jika ada barang yang rusak dan perlu diperbaiki, atau hal-hal yang belum dimiliki masjid, dan lain-lain.

Sesi kedua, remaja masjid dijelaskan tentang proses pengelolaan keuangan masjid. Pengelolaan keuangan masjid adalah hal yang penting karena masjid menerima berbagai macam sumber pendanaan. Masjid Al Ikhlas tidak hanya mengelola infaq dan shodaqoh dari jamaah namun juga zakat. Berdasarkan hukumnya uang zakat tidak boleh digunakan untuk keperluan masjid, namun hanya diperuntukkan kepada delapan (8) ashnaf. Hal tersebut sesuai dengan ayat yang disampaikan oleh Al Quran yaitu : "Sesungguhnya zakat itu hanyalah untuk orang-orang fakir, orang-orang miskin, pengurus-pengurus zakat, para muallaf, yang dibujuk hatinya,untuk (memerdekakan) budak, orang-orang yang berutang, untuk jalan Allah, dan orang-orang yang sedang dalam perjalanan, sebagai suatu ketetapan yang diwajibkan Allah. Dan Allah Maha Mengetahui Lagi Maha Bijaksana." (Q.S. At-Taubah:60). Berdasarkan golongan tersebut maka uang zakat tidak diperbolehkan digunakan untuk keperluan masjid, dan pencatatan harus terpisah dengan shadaqoh dan infaq.

Pencatatan keuangan tidak hanya berkaitan dengan pemasukan masjid namun juga pengeluaran masjid. Setiap pengeluaran yang dilakukan alangkah lebih baik jika direncanakan terlebih dahulu, sehingga pengeluaran masjid tidak melebihi kapasitas keuangan yang dimiliki oleh masjid.

Sesi ketiga adalah proses pengelolaan SDM. Pengelolaan SDM dilaksanakan dengan memberikan pelatihan kepada pengurus masjid agar masjid menjadi semakin makmur dengan program-program yang diberikan kepada jamaah. Proses perencanaan dan pengelolaan event membutuhkan pengetahuan dan ketrampilan sehingga setiap tahun remaja masjid harus mengagendakan program pelatihan. Hal tersebut dimaksudkan agar masjid memberikan kajian, seminar, maupun program yang inovatif, kreatif, dan bermanfaat bagi jamaah dengan didukung fasilitas dan pengelolaan masjid yang baik.

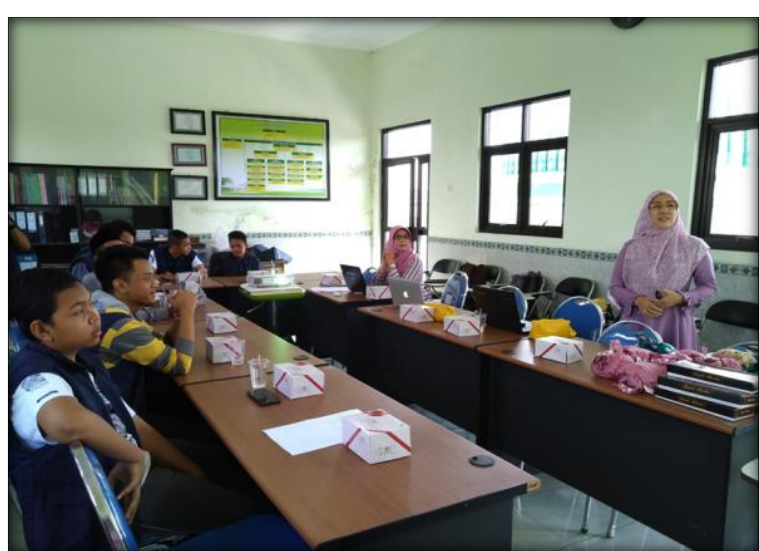

Gambar 1. Pelatihan Aset Masjid

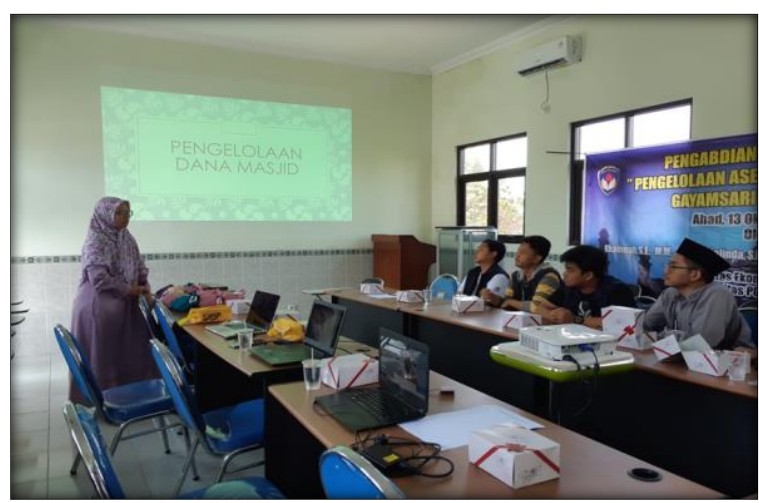

Gambar 2. Pelatihan Pengelolaan Keuangan Masjid

\section{SIMPULAN}

Pengelolaan aset merupakan hal yang penting untuk mengetahui harta benda yang dimiliki masjid. Proses ini tidak hanya untuk mengetahui posisi harta benda yang dimiliki namun juga harta benda yang rusak/hilang. Pengelolaan keuangan masjid juga merupakan proses untuk pencatatan pemasukan dan pengeluaran masjid. Dalam proses pencatatan pemasukan, pos-pos keuangan yang masuk harus dipisahkan terutama untuk uang zakat dan infaq/shodakoh. Proses pengeluaran keuangan harus disesuaikan dengan perencanaan yang dilakukan setiap awal tahun. Selain itu, juga perlu untuk diperhatikan proses pengelolaan SDM sebagai upaya untuk meningkatkan pengetahuan dan skill pengurus masjid agar dapat memberikan program, pelatihan, seminar, maupun kajian rutin secara menarik, kreatif, dan bermanfaat, sehingga dapat meningkatkan antusias jamaah dalam berkegiatan di masjid. 


\section{DAFTAR PUSTAKA}

Abshari, A. F. (2011). Strategi Masjid Dalam Pemberdayaan Ekonomi Umat (Studi Pada Masjid Raya Pondok Indah dan Masjid Jami'Bintaro Jaya). (Skripsi tidak dipublikasikan). Fakultas Syariah dan Hukum, UIN Syarif Hidayatullah, Jakarta.

Alwi, M. M. (2015). Optimalisasi Fungsi Masjid Dalam Pemberdayaan Ekonomi Masyarakat. Al-Tatwir, 2(1), 133-152.

Auliyah, R. (2014). Studi Fenomenologi Peranan Manajemen Masjid At-Taqwa dalam Pemberdayaan Ekonomi Masyarakat Bangkalan. Competence: Journal of Management Studies, 8(1), 7491.

https://doi.org/10.21107/kompetensi.v8i1. 650.

Dalmeri, D. (2014). Revitalisasi Fungsi Masjid Sebagai Pusat Ekonomi Dan Dakwah Multikultural. Walisongo: Jurnal Penelitian Sosial Keagamaan, 22(2), 321-350.

https://doi.org/10.21580/ws.22.2.269.

Fahmi, F. A., \& Qulub, A. S. U. (2017). Pelaksanaan Fungsi Manajemen (Planning, Organizing, Actualling, Controlling) Pada Manajemen Masjid AlAkbar Surabaya. Jurnal Ekonomi Syariah Teori dan Terapan, 4(12), 968. http://dx.doi.org/10.20473/vol4iss201712 pp968-976.

Jannah, N. (2016) Revitalisasi Peranan Masjid di Era Modern (studi kasus di Kota Medan). (Masters thesis tidak dipublikasikan), Pascasarjana UIN Sumatera Utara, Medan.

Ikhwan, A. (2013). Optimalisasi Peran Masjid Dalam Pendidikan Anak: Perspektif Makro Dan Mikro. Edukasi: Jurnal Pendidikan Islam, 1(1), 1-16.

Ridwanullah, A. I., \& Herdiana, D. (2018). Optimalisasi Pemberdayaan Masyarakat Berbasis Masjid. Ilmu Dakwah: Academic Journal for Homiletic Studies, 12(1), https://doi.org/10.15575/idajhs.v12i1.239 6.

Sofwan, R. (2013). Penguatan Manajemen Pemberdayaan Fungsi Masjid Al-Fattah di Kelurahan Krapyak Semarang. Dimas: Jurnal Pemikiran Agama untuk Pemberdayaan, 13(2), 315-334. 